\title{
Factors Influencing Clinicians' Willingness to Prescribe Pre-exposure Prophylaxis for Persons at High Risk of HIV in China: Cross-sectional Online Survey Study
}

Sitong Cui ${ }^{1,2,3,4^{*}}$, MPH; Haibo Ding ${ }^{1,2,3,4^{*}}, \mathrm{PhD}$; Xiaojie Huang ${ }^{5}$, PhD; Hui Wang ${ }^{6}, \mathrm{PhD}$; Weiming Tang ${ }^{7}, \mathrm{PhD}$; Sequoia I Leuba $^{8}$, PhD; Zehao Ye ${ }^{1,2,3,4}$, MPH; Yongjun Jiang ${ }^{1,2,3,4}, \mathrm{PhD}$; Wenqing Geng ${ }^{1,2,3,4}$, PhD; Junjie Xu ${ }^{1,2,3,4}, \mathrm{PhD}$; Hong Shang ${ }^{1,2,3,4}, \mathrm{PhD}$

${ }^{1}$ NHC Key Laboratory of AIDS Immunology (China Medical University), National Clinical Research Center for Laboratory Medicine, The First Affiliated Hospital of China Medical University, Shenyang, Liaoning Province, China

${ }^{2}$ Key Laboratory of AIDS Immunology, Chinese Academy of Medical Sciences, Shenyang, China

${ }^{3}$ Key Laboratory of AIDS Immunology of Liaoning Province, Shenyang, China

${ }^{4}$ Collaborative Innovation Center for Diagnosis and Treatment of Infectious Diseases, Hangzhou, China

${ }^{5}$ Center for Infectious Diseases, Beijing You'an Hospital, Capital Medical University, Beijing, China

${ }^{6}$ Shenzhen Third People's Hospital, Shenzhen, China

${ }^{7}$ Project-China, University of North Carolina at Chapel Hill, Guangzhou, China

${ }^{8}$ Department of Epidemiology, University of North Carolina at Chapel Hill, Chapel Hill, NC, United States

*these authors contributed equally

\section{Corresponding Author:}

Hong Shang, PhD

NHC Key Laboratory of AIDS Immunology (China Medical University)

National Clinical Research Center for Laboratory Medicine

The First Affiliated Hospital of China Medical University

No 155, Nanjing North Street, Heping District

Shenyang, Liaoning Province, 110001

China

Phone: 8683282634

Fax: 8683282634

Email: hongshang100@ hotmail.com

\section{Abstract}

Background: Pre-exposure prophylaxis (PrEP) is an effective HIV prevention measure. Clinicians play a crucial role in PrEP implementation, and their knowledge, attitudes, and career experience may affect their willingness to prescribe PrEP. However, little is known about the attitudes and willingness of clinicians to prescribe PrEP in countries without PrEP-specific guidelines.

Objective: We aimed to determine the factors associated with clinicians being willing to prescribe PrEP in China.

Methods: Between May and June 2019, we conducted an online cross-sectional survey of clinicians in 31 provinces across the six administrative regions in China on the WeChat smartphone app platform. Multivariable logistic regression was used to determine factors associated with willingness to prescribe PrEP.

Results: Overall, 777 HIV clinicians completed the survey. Most of the respondents had heard of PrEP (563/777, 72.5\%), 31.9\% (248/777) thought that PrEP was extremely effective for reducing the risk of HIV infection, and 47.2\% (367/777) thought that it was necessary to provide PrEP to high-risk groups. After adjusting for age, gender, ethnicity, and educational background of the clinicians, the following factors significantly increased the odds of the clinicians being willing to prescribe PrEP: having worked for more than 10 years, compared to 5 years or less (adjusted odds ratio [aOR] 2.82, 95\% CI 1.96-4.05); having treated more than 100 patients living with HIV per month, compared to 50 patients or fewer (aOR 4.16, 95\% CI 2.85-6.08); and having heard of PrEP (aOR 7.32, 95\% CI 4.88-10.97). Clinicians were less likely to be willing to prescribe PrEP if they were concerned about poor adherence to PrEP (aOR 0.66, 95\% CI 0.50-0.88), the lack of PrEP clinical guidelines (aOR 0.47, 95\% CI 0.32-0.70), and the lack of drug indications for PrEP (aOR 0.49, 95\% CI 0.32-0.76). 
Conclusions: About half of all clinicians surveyed were willing to prescribe PrEP, but most surveyed had a low understanding of PrEP. Lack of PrEP clinical guidelines, lack of drug indications, and less than 11 years of work experience were the main barriers to the surveyed clinicians' willingness to prescribe PrEP. Development of PrEP clinical guidelines and drug indications, as well as increasing the availability of PrEP training, could help improve understanding of PrEP among clinicians and, thus, increase the number willing to prescribe PrEP.

(JMIR Public Health Surveill 2021;7(6):e24235) doi: 10.2196/24235

\section{KEYWORDS}

WeChat; pre-exposure prophylaxis; clinicians; willingness to prescribe; HIV prevention; China

\section{Introduction}

Pre-exposure prophylaxis (PrEP) is a highly effective preventative strategy for HIV; through a combination of HIV approaches recommended by the World Health Organization (WHO), PrEP can reduce HIV transmission [1]. PrEP strategies involve key HIV-negative populations who take antiretroviral medications and attend routine visits with an HIV clinician in order to prevent HIV transmission. Recent clinical trials among men who have sex with men (MSM) have shown that daily oral PrEP and on-demand PrEP can prevent $86 \%$ and $96 \%$ of HIV infections, respectively [2]. Tenofovir disoproxil fumarate/emtricitabine (TDF/FTC; brand name Truvada) has been approved by the WHO for PrEP use among adults and adolescents at risk of HIV [3,4]. About 40 countries around the world have incorporated PrEP into their health systems, 10 of which have carried out nationwide programs [2]. The other 30, including China, are implementing pilot projects exploring the acceptability, effectiveness, and cost of PrEP [2,5]. At present, only a few countries have provided support on implementing this new strategy through country-specific guidelines for clinicians $[3,6]$.

Before prescribing PrEP, physicians must assess the HIV risk of the patient, their likely adherence, and any potential side effects in order to ensure effective use of PrEP [7-10]. PrEP is most effective at reducing HIV risk when targeted toward high-risk populations [6]. Assessing likely adherence is crucial, as patients with low adherence to PrEP did not have a reduction in HIV risk [11]. In addition, as some high-risk populations have anxiety and depression [12], any potential side effects of PrEP must be assessed by the clinician prior to prescribing PrEP. Thus, any support in making these judgments before prescribing is needed.

One potential method to support clinicians in prescribing PrEP is through providing clinical guidelines to standardize HIV risk assessment. In countries where national PrEP clinical guidelines have been issued, physicians weigh PrEP-related knowledge, attitudes, and experiences when making their decision to prescribe PrEP [13,14]. Some developed countries (eg, the United States, the United Kingdom, and Canada) have examined the attitudes and intentions to prescribe PrEP among clinicians through investigations [15-22]. However, in low- and middle-income countries that do not have national PrEP clinical guidelines, clinicians' knowledge and willingness to prescribe PrEP has not previously been well-reported.
Despite the high burden caused by the HIV epidemic, China has been slower to implement PrEP compared to other developed countries [2], and few studies have evaluated PrEP use in China. The National Health Commission in China has stated that the country needs to promote PrEP implementation by carrying out nationwide pilot work. The Chinese Center for Disease Control and Prevention has established pilot projects in seven provinces, running from October 2008 to November 2019, to study the feasibility of using PrEP in key populations [23]. In addition, China Medical University carried out real-world research of PrEP use among MSM in Shenyang, Beijing, Chongqing, and Shenzhen starting in December 2018; this research concluded in December 2020 [24]. In addition to these real-world studies on PrEP implementation, several studies have also shown that Chinese MSM are very willing to use PrEP [25,26]. However, the current proportion of PrEP prescriptions in key populations in China is less than $1 \%$, much lower than that in other developed countries $(9.5 \%$ in the United States and $2.5 \%$ in Australia) [27]. Clinicians may be reluctant to prescribe PrEP because of limited understanding, thus leading to this low percentage of prescriptions among key groups in China.

To evaluate PrEP-related attitudes among Chinese clinicians, we conducted a nationwide online survey investigating PrEP-related awareness and attitudes, experience with PrEP, and potential perceived barriers to being willing to prescribe PrEP.

\section{Methods}

\section{Respondents and Procedures}

Between May and June 2019, we conducted a nationwide anonymous online survey among Chinese HIV clinicians in 31 provinces across six administrative regions. The questionnaire was designed based on current literature of HIV prevention using PrEP in China and with the support of subject matter experts. Clinicians with clinical medical qualifications were eligible for the study if they were currently working in a position at an infectious disease or general hospital that included treating patients living with HIV. We reached out to HIV clinicians through the two largest professional work groups in China on WeChat, the most popular social media app in China: the National clinicians group focusing on HIV/AIDS and the National physician platform for the communication of difficult HIV/AIDS cases. The administrators of these two WeChat groups confirmed the clinical identities and specialties of their members, and removed any members with nonclinical identifications. Thus, 937 HIV clinicians were eligible for this survey (Multimedia Appendix 1). After conducting a pilot study 
with 50 eligible participants by convenience sampling, which was included in the final results, we evaluated the accuracy and reliability of the questionnaire and modified the survey accordingly. To recruit participants from the remaining eligible clinicians, we posted a brief description of the survey, including the purpose and significance, and links to the questionnaire. The inclusion criteria for this survey were as follows: (1) 18 years of age or older, (2) practicing in an HIV-related medical institution, and (3) treated at least one person living with HIV over the past year. Based on the open ID of WeChat, each individual was allowed to access the online survey only once and the answers could be reviewed or changed before submission. We confirmed the identity of participants through collected self-reported information about medical background and relevant experience. After submission of the completed questionnaire, we provided a subsidy of 30 Yuan (US \$4.50) to participants to compensate for the time they spent completing the survey (ie, about 6 to 10 minutes). We used self-reported contact information only to deliver the subsidy. Ethical approval was obtained from the Institutional Review Board of the First Affiliated Hospital of China Medical University ([2019]2015-138-9). In our analysis, we followed the CHERRIES (Checklist for Reporting Results of Internet E-Surveys) guidelines (Multimedia Appendix 2).

\section{Measures}

After providing online informed consent, clinicians completed a voluntary anonymous survey. The questionnaire asked about sociodemographic characteristics; medical background; PrEP-related knowledge, attitudes, and experience; and barriers to prescribing PrEP (Multimedia Appendix 3).

The primary outcome of this study was the percentage of clinicians willing to prescribe PrEP to key populations based on their response-yes or no-to the following question: "Do you think it is necessary for clinicians to provide PrEP to HIV high-risk populations to reduce HIV infections?" The questionnaire also asked about the location, administrative level, and type of hospital where they practiced; their academic title; length of their career; and the average number of patients living with HIV treated in the past month. We then assessed PrEP-related knowledge: whether participants had ever heard of PrEP, their understanding of PrEP, how effective they thought PrEP was for reducing the risk of HIV infections, and whether clinical guidelines for PrEP were available in China. We also asked how often they recommend PrEP to MSM, heterosexual males, heterosexual females, and serodiscordant couples.
Respondents were also asked how often they saw high-risk groups actively seeking a PrEP prescription in the past 6 months and potential barriers to them prescribing PrEP.

\section{Statistical Analysis}

Continuous variables were categorized for analysis. Age was grouped into five categories $(25,26-39,40-49,50-59$, and 60 years), length of career was grouped into three categories (5, 6-10, and 11 years), and average number of patients living with HIV treated per month was also grouped into three categories (50, 51-100, and 101 patients). We described the distribution of the variables by presenting the frequency and percentage. We then conducted univariable and multivariable logistic regression to determine predictors of clinicians being willing to prescribe PrEP and presented crude odds ratios (ORs) and adjusted ORs (aORs) with the corresponding 95\% CIs. If there were no clinicians in a specific cell in a comparison, 0.5 was added to all cells to compute the OR [28]. Significant predictors in the univariable analysis were included in the multivariable logistic regression. We adjusted for age, gender, ethnicity, and educational background of the clinician in the multivariable model. All statistical analyses were performed with SPSS, version 25.0 (IBM Corp). A two-tailed $P$ value of less than .05 was considered statistically significant.

\section{Results}

\section{Demographic and Medical Background Characteristics}

A total of 777 eligible clinicians completed the survey, which represented a response rate of $82.9 \%$ (777/937) (Multimedia Appendix 1). Among these 777 survey responses, 50 (6.4\%) were from the pilot survey. The median age of the participants was 42 years (IQR 36-48), around half were female (417/777, $53.7 \%)$, the most common ethnicity was Han (712/777, 91.6\%), and most had a bachelor's degree or above $(743 / 777,95.6 \%)$. The highest proportion of participants were from South Central China (201/777, 25.9\%). The distribution of HIV clinicians surveyed at the province level and economic level is included in Multimedia Appendix 4. Approximately half of the participants worked in infectious disease hospitals (394/777, $50.7 \%$ ), and $54.2 \%$ (421/777) were deputy chief physicians or chief physicians. Slightly more than half $(432 / 777,55.6 \%)$ had worked for more than 5 years, and $59.3 \%(461 / 777)$ treated an average of 50 or fewer patients living with HIV per month (Table 1). 
Table 1. Demographic and medical background characteristics of clinicians.

\begin{tabular}{|c|c|}
\hline Characteristic & Value $(\mathrm{N}=7$ \\
\hline \multicolumn{2}{|l|}{ Demographic characteristic } \\
\hline \multicolumn{2}{|l|}{ Age (years) } \\
\hline$\leq 25$ & $3(0.4)$ \\
\hline $26-39$ & $302(38.9)$ \\
\hline $40-49$ & $331(42.6)$ \\
\hline $50-59$ & $131(16.9)$ \\
\hline$\geq 60$ & $10(1.3)$ \\
\hline \multicolumn{2}{|l|}{ Ethnicity } \\
\hline Han & $712(91.6)$ \\
\hline Non-Han & $65(8.4)$ \\
\hline \multicolumn{2}{|l|}{ Gender } \\
\hline Male & $360(46.3)$ \\
\hline Female & $417(53.7)$ \\
\hline \multicolumn{2}{|l|}{ Administrative region of China ${ }^{a}$} \\
\hline South Central & $201(25.9)$ \\
\hline Southwest & 199 (25.6) \\
\hline Northeast & $164(21.1)$ \\
\hline East & $116(14.9)$ \\
\hline North & $71(9.1)$ \\
\hline Northwest & $26(3.3)$ \\
\hline \multicolumn{2}{|l|}{ Education level } \\
\hline Technical secondary school & $5(0.6)$ \\
\hline Junior college & $29(3.7)$ \\
\hline Bachelor's degree or above & 743 (95.6) \\
\hline
\end{tabular}

Medical background and experience

Type of hospital

\section{General}

Infectious disease

\section{Academic title}

General physician

Attending doctor

Deputy chief physician

Chief physician

Specialization

HIV

General infectious diseases

\section{Length of career (years)}

$\leq 5$

6-10

$\geq 11$

Average number of patients living with HIV treated per month

$\leq 50$
$383(49.3)$

$394(50.7)$

$82(10.6)$

$274(35.3)$

$221(28.4)$

$200(25.7)$

$649(83.5)$

$128(16.5)$

$345(44.4)$

$184(23.7)$

$248(31.9)$

$461(59.3)$ 


\begin{tabular}{cl}
\hline Characteristic & Value (N=777), $\mathrm{n}(\%)$ \\
\hline $51-100$ & $128(16.5)$ \\
$\geq 101$ & $188(24.2)$ \\
\hline
\end{tabular}

${ }^{\mathrm{a}}$ The 31 provinces were located across six administrative regions.

\section{Self-Rated Knowledge, Attitudes, and Experience Associated With PrEP and Barriers to Prescribing}

In this study, $72.5 \%(563 / 777)$ of the clinicians reported that they had heard of PrEP; however, only $30.8 \%$ (239/777) had an excellent or good understanding of PrEP, and $31.9 \%$ (248/777) thought that PrEP was extremely effective for reducing the risk of HIV infection. Most clinicians (635/777, $81.7 \%$ ) considered that PrEP clinical guidelines were not available in China. About half $(367 / 777,47.2 \%)$ believed that it was necessary for clinicians to provide PrEP to HIV high-risk populations to reduce HIV infections and were, thus, defined as willing to prescribe PrEP. Clinicians were more likely to mostly recommend PrEP to serodiscordant couples (439/777,
$56.5 \%$ ), followed by MSM (309/777, 39.8\%). Few clinicians (201/777, 25.9\%) often or occasionally saw high-risk populations actively seeking PrEP prescriptions. Among the clinicians surveyed, concerns about prescribing PrEP included the following: side effects of treatment (484/777, 62.3\%), promoting the occurrence of high-risk sexual behaviors $(476 / 777,61.3 \%)$, and poor adherence to $\operatorname{PrEP}(383 / 777,49.3 \%)$ (Table 2).

Figure 1 depicts the six administrative regions of China; the percentages of clinicians from these regions who self-reported an excellent or good understanding of PrEP, who found that PrEP was necessary for high-risk groups, and who treated 50 or fewer patients living with HIV per month are shown in Table 3 . 
Table 2. Self-rated knowledge, attitudes, experience, and barriers associated with pre-exposure prophylaxis (PrEP).

\begin{tabular}{ll}
\hline Variable & Value $(\mathrm{N}=777), \mathrm{n}(\%)$ \\
\hline Self-rated knowledge & \\
Heard of PrEP & $563(72.5)$ \\
Yes & $214(27.5)$ \\
No & \\
Understanding of PrEP & $86(11.1)$ \\
Excellent & $153(19.7)$ \\
Good & $538(69.2)$ \\
Low & \\
Effectiveness of PrEP on reducing the risk of HIV infection & $248(31.9)$ \\
Extremely effective & $106(13.6)$ \\
Possibly effective & $419(53.9)$ \\
Not sure & $4(0.5)$ \\
Ineffective & \\
PrEP clinical guidelines are available in China & $142(18.3)$ \\
Yes & $635(81.7)$ \\
No &
\end{tabular}

\section{Attitudes towards PrEP}

Providing PrEP to high-risk groups

Necessary

$367(47.2)$

Not necessary

Recommend PrEP prescription to men who have sex with men

Mostly

Frequently

Seldom

Never

Recommend PrEP prescription to heterosexual males

Mostly

Frequently

Seldom

Never

Recommend PrEP prescription to heterosexual females

Mostly

Frequently

Seldom

Never

Recommend PrEP prescription to serodiscordant couples

Mostly
Frequently
Seldom
Never

Never

Experience related to PrEP

See high-risk groups actively seeking PrEP prescriptions
$352(45.3)$

$153(19.7)$

$410(52.8)$

$309(39.8)$

$254(32.7)$

$55(7.1)$

$159(20.5)$

$59(7.6)$

$309(39.8)$

$154(19.8)$

$255(32.8)$

$214(27.5)$

439 (56.5)

$197(25.4)$

58 (7.5)

$83(10.7)$ 


\begin{tabular}{ll}
\hline Variable & Value $(\mathrm{N}=777), \mathrm{n}(\%)$ \\
\hline Often & $50(6.4)$ \\
Occasionally & $151(19.4)$ \\
Seldom & $213(27.4)$ \\
Never & $363(46.7)$
\end{tabular}

Perceived barriers to prescribing PrEP

Concerned about promoting the occurrence of high-risk sexual behaviors
Yes
$476(61.3)$
No
$301(38.7)$

Concerned about increasing the risk of other sexually transmitted diseases

Yes

No

657 (84.6)

Concerned about p oor adherence to PrEP

Yes

No

$394(50.7)$

Concerned about drug resistance

Yes

$271(34.9)$

No

$506(65.1)$

Concerned about side effects of PrEP

Yes

No

293 (37.7)

Concerned about the cost of PrEP

Yes

$462(59.5)$

No

$315(40.5)$

Concerned about reduction of resources for patients living with HIV

Yes

No

$654(84.2)$

Concerned about lack of PrEP clinical guidelines

Yes

$140(18.0)$

No

$637(82.0)$

Concerned about $l$ ack of drug indications

Yes

$108(13.9)$

No

$669(86.1)$ 
Figure 1. The six administrative regions of China.

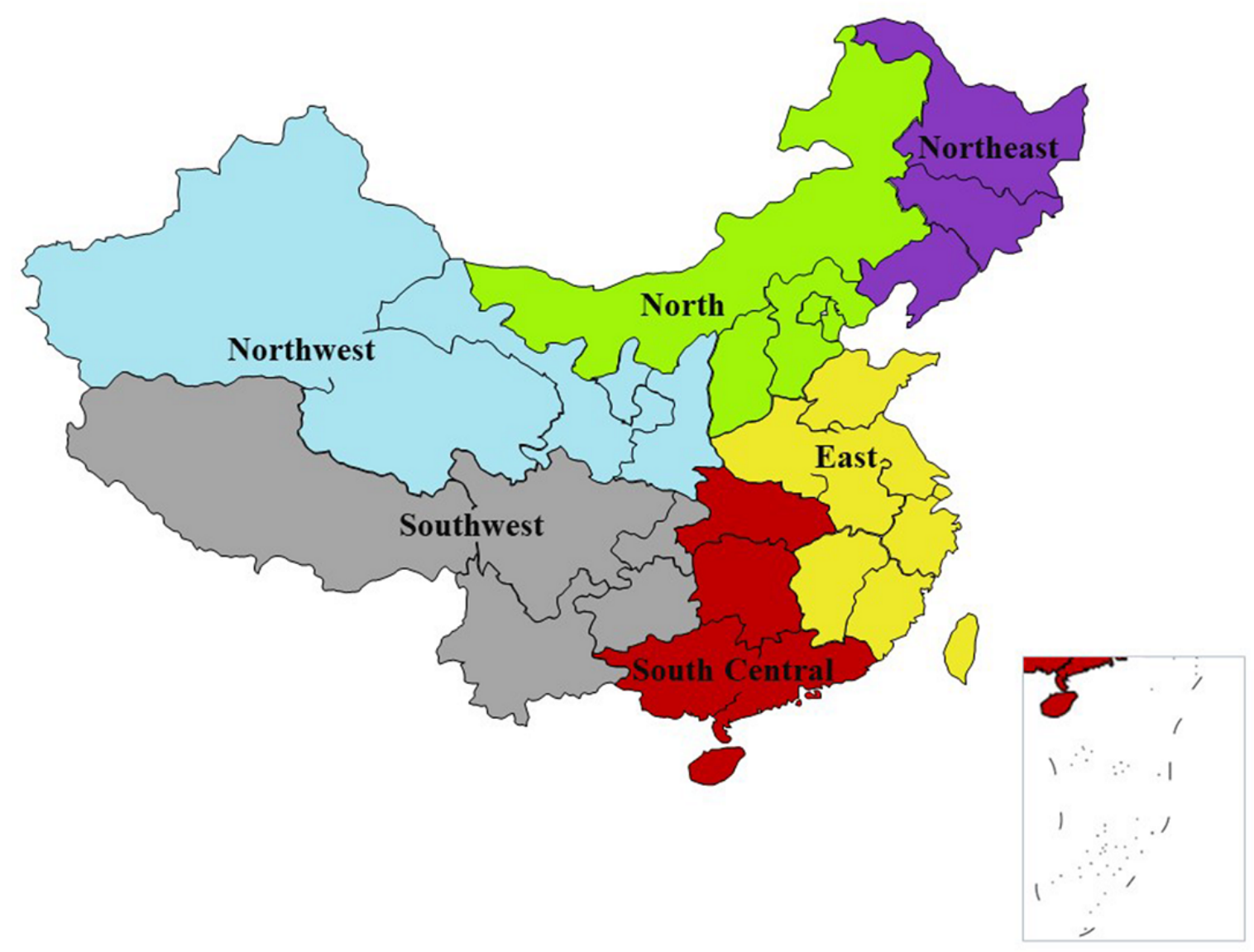


Table 3. Pre-exposure prophylaxis (PrEP)-related knowledge, attitudes, and medical experience of clinicians in six administrative regions of China.

\begin{tabular}{|c|c|}
\hline Variable and regions of China & Value, $\mathrm{n}(\%)$ \\
\hline \multicolumn{2}{|l|}{ Self-reported an excellent or good understanding of PrEP } \\
\hline South Central $(\mathrm{n}=201)$ & $63(31.3)$ \\
\hline Southwest $(n=199)$ & $58(29.1)$ \\
\hline Northeast $(n=164)$ & 49 (29.9) \\
\hline East $(n=116)$ & $39(33.6)$ \\
\hline North $(n=71)$ & $21(29.6)$ \\
\hline Northwest $(\mathrm{n}=26)$ & $9(34.6)$ \\
\hline \multicolumn{2}{|l|}{ PrEP was necessary for high-risk groups } \\
\hline South Central $(n=201)$ & $95(47.3)$ \\
\hline Southwest $(\mathrm{n}=199)$ & $90(45.2)$ \\
\hline Northeast $(n=164)$ & $87(53.0)$ \\
\hline East $(n=116)$ & $54(46.6)$ \\
\hline North $(n=71)$ & $26(36.6)$ \\
\hline Northwest $(\mathrm{n}=26)$ & $15(57.7)$ \\
\hline \multicolumn{2}{|l|}{ Treated 50 or fewer patients living with HIV per month } \\
\hline South Central $(n=201)$ & $135(67.2)$ \\
\hline Southwest $(n=199)$ & $108(54.3)$ \\
\hline Northeast $(n=164)$ & $90(54.9)$ \\
\hline East $(n=116)$ & $69(59.5)$ \\
\hline North $(n=71)$ & $40(56.3)$ \\
\hline Northwest $(n=26)$ & $19(73.1)$ \\
\hline $\begin{array}{l}\text { Predictors of Clinicians Being Willing to Prescribe } \\
\text { PrEP }\end{array}$ & $\begin{array}{l}\text { compared to never requesting }(\mathrm{aOR} 79.35,95 \% \quad \mathrm{CI} \\
18.78-335.31) \text {. }\end{array}$ \\
\hline $\begin{array}{l}\text { Table } 4 \text { presents the crude ORs of potential factors that could } \\
\text { affect clinicians' willingness to prescribe PrEP. All significant } \\
\text { factors in the crude analysis were analyzed using multivariable } \\
\text { logistic regression (Figure 2). After adjusting for age, gender, } \\
\text { ethnicity, and educational background, the following clinicians } \\
\text { were more likely to be willing to prescribe PrEP: those who } \\
\text { had been working for more than } 10 \text { years, compared to } 5 \text { years } \\
\text { or fewer (aOR } 2.82,95 \% \text { CI 1.96-4.05); those who heard of } \\
\text { PrEP (aOR } 7.32,95 \% \text { CI } 4.88-10.97 \text { ); and those who often had } \\
\text { high-risk populations actively requesting PrEP prescriptions, }\end{array}$ & $\begin{array}{l}\text { Clinicians who had a low understanding of PrEP, compared to } \\
\text { an excellent understanding (aOR } 0.04,95 \% \text { CI } 0.02-0.10 \text { ), or } \\
\text { were not sure about the effectiveness of PrEP on reducing the } \\
\text { risk of HIV infection, compared to self-reporting PrEP as } \\
\text { extremely effective (aOR } 0.05,95 \% \text { CI } 0.04-0.08 \text { ), were less } \\
\text { likely to be willing to prescribe PrEP. In addition, clinicians } \\
\text { who were concerned about the lack of PrEP clinical guidelines } \\
\text { (aOR } 0.47,95 \% \text { CI } 0.32-0.70 \text { ) or the lack of drug indications } \\
\text { (aOR } 0.49,95 \% \text { CI } 0.32-0.76 \text { ) were less likely to be willing to } \\
\text { prescribe PrEP. }\end{array}$ \\
\hline
\end{tabular}


Table 4. Univariable logistic regression of predictors of clinicians being willing to prescribe pre-exposure prophylaxis $(\operatorname{PrEP})(\mathrm{N}=777)$.

\begin{tabular}{llll}
\hline Variable & Willing to prescribe PrEP & Odds ratio (95\% CI) & $P$ value \\
& Yes $(\mathrm{n}=367), \mathrm{n}(\%)$ & No $(\mathrm{n}=410), \mathrm{n}(\%)$ & \\
\hline
\end{tabular}

\section{Age (years)}

26-39

$\leq 25$

40-49

50-59

$\geq 60$

Ethnicity

Han

Administrative region of China

Northeast

South Central

Southwest

East

North

Northwest

Type of hospital

General
Infectious disease

Academic title

General physician
Attending doctor
Deputy chief physician
Chief physician

Length of career (years)

$\begin{array}{lll}\leq 5 & 129(35.1) & 216(52.7) \\ 6-10 & 85(23.2) & 99(24.1) \\ \geq 11 & 153(41.7) & 95(23.2)\end{array}$

Average number of patients living with HIV treated per month

$\leq 50$
$51-100$
$\geq 101$

Heard of PrEP

No

Yes

$180(49.0)$

$134(36.5)$

$37(10.1)$

$330(89.9)$

U nderstanding of PrEP

$\begin{array}{ll}\text { Excellent } & 79(21.5) \\ \text { Good } & 97(26.4) \\ \text { Low } & 191(52.0)\end{array}$

Effectiveness of PrEP on reducing the risk of HIV infection
$281(68.5)$

75 (18.3)

54 (13.2)

177 (43.2)

$233(56.8)$

$156(38.0)$
$3(0.7)$
$190(46.3)$
$55(13.4)$
$6(1.5)$

375 (91.5)

87 (21.2)

$95(23.2)$

$110(26.8)$

$62(15.1)$

$45(11.0)$

$213(52.0)$

197 (48.0)

45 (11.0)

$132(32.2)$

$126(30.7)$

$107(26.1)$

7 (1.7)

56 (13.7)

347 (84.6)
$206(56.1)$
Reference

$0.15(0.01-2.98) \quad .22$

$0.79(0.58-1.09) \quad .15$

$1.48(0.98-2.23) \quad .07$

$0.71(0.20-2.58) \quad .61$

Reference

$0.96(0.57-1.59) \quad .86$

Reference

$1.26(0.83-1.91) \quad .27$

$0.91(0.60-1.38) \quad .67$

$0.98(0.61-1.59) \quad .95$

$0.65(0.37-1.16) \quad .14$

$1.54(0.67-3.56) \quad .31$

\section{Reference}

$1.25(0.95-1.66)$

.12

Reference

$1.31(0.80-2.15) \quad .29$

$0.92(0.55-1.53) \quad .74$

$1.06(0.63-1.77) \quad .83$

Reference

$1.44(1.00-2.07) \quad .05$

$2.70(1.93-3.78)<<.001$

Reference

$1.10(0.74-1.64) \quad .63$

$3.87(2.68-5.59) \quad<.001$

Reference

$6.78(4.58-10.03)<.001$

Reference

$0.15(0.07-0.36) \quad<.001$

$0.05(0.02-0.11) \quad<.001$
Extremely effective
Reference 


\begin{tabular}{|c|c|c|c|c|}
\hline \multirow[t]{2}{*}{ Variable } & \multicolumn{2}{|c|}{ Willing to prescribe PrEP } & \multirow[t]{2}{*}{ Odds ratio $(95 \% \mathrm{CI})$} & \multirow[t]{2}{*}{$P$ value } \\
\hline & Yes $(n=367), n(\%)$ & No $(n=410), n(\%)$ & & \\
\hline Possibly effective & $68(18.5)$ & $38(9.3)$ & $0.37(0.22-0.61)$ & $<.001$ \\
\hline Not sure & $91(24.8)$ & $328(80.0)$ & $0.06(0.04-0.09)$ & $<.001$ \\
\hline Ineffective & $2(0.5)$ & $2(0.5)$ & $0.20(0.03-1.49)$ & .12 \\
\hline \multicolumn{5}{|c|}{ See high-risk groups actively seeking PrEP prescriptions } \\
\hline Never & $88(24.0)$ & $275(67.1)$ & Reference & \\
\hline Seldom & $111(30.2)$ & $102(24.9)$ & $3.40(2.37-4.88)$ & $<.001$ \\
\hline Occasionally & $120(32.7)$ & $31(7.6)$ & $12.10(7.62-19.20)$ & $<.001$ \\
\hline Often & $48(13.1)$ & $2(0.5)$ & $75.00(17.86-314.88)$ & $<.001$ \\
\hline
\end{tabular}

Concerned about promoting the occurrence of high-risk sexual behaviors

$\begin{array}{llll}\text { No } & 152(41.4) & 149(36.3) & \text { Reference } \\ \text { Yes } & 215(58.6) & 261(63.7) & 0.81(0.61-1.08)\end{array}$

Concerned about increasing the risk of other sexually transmitted diseases
No
$332(90.5)$
325 (79.3)
Reference
Yes
$35(9.5)$
85 (20.7)
$0.40(0.26-0.62)$
$<.001$

Concerned about poor adherence to PrEP

No

Yes

$206(56.1)$

161 (43.9)

188 (45.9)

$222(54.1)$

143 (39.0)

150 (36.6)

$260(63.4)$

$224(61.0)$

Yes

Concerned about lack of PrEP clinical guidelines
No
322 (87.7)
45 (12.3)

$315(76.8)$

95 (23.2)

$333(90.7)$

$336(82.0)$

$34(9.3)$

74 (18.0)

Yes

$74(18.0)$

\section{Reference}

$0.66(0.50-0.88)$

.004

Reference

$0.90(0.68-1.21)$

Reference

$0.46(0.32-0.68)$

Reference

$0.46(0.30-0.72)$

.001 
Figure 2. Predictors of clinicians being willing to prescribe pre-exposure prophylaxis (PrEP) (N=777). aOR: adjusted odds ratio; Ref.: reference; STD: sexually transmitted disease.

\begin{tabular}{|c|c|c|c|c|c|}
\hline \multirow[t]{2}{*}{ Variables } & \multirow{2}{*}{$\begin{array}{c}\text { Willing to prescribe PrEP } \\
\text { n (\%) }\end{array}$} & \multicolumn{3}{|c|}{ Multivariable analysis } & \multirow{2}{*}{$P$ value } \\
\hline & & \multicolumn{3}{|c|}{ aOR $(95 \% \mathrm{CI})$} & \\
\hline \multicolumn{6}{|c|}{ Length of career (years) } \\
\hline$\leq 5$ & $129(35.1)$ & & & Ref. & \\
\hline $6-10$ & $85(23.2)$ & & $=-1$ & $1.42(0.98-2.05)$ & .06 \\
\hline$\geq 11$ & $153(41.7)$ & & $\mapsto-1$ & $2.82(1.96-4.05)$ & $<.001$ \\
\hline \multicolumn{6}{|c|}{ Average number of patients living with HIV treated per month } \\
\hline$\leq 50$ & $180(49.0)$ & & & Ref. & \\
\hline $51-100$ & $53(14.4)$ & & - & $1.15(0.76-1.73)$ & .50 \\
\hline$\geq 101$ & $134(36.5)$ & & $\mapsto-1$ & $4.16(2.85-6.08)$ & $<.001$ \\
\hline \multicolumn{6}{|l|}{ Heard of PrEP } \\
\hline No & $37(10.1)$ & & & Ref. & \\
\hline Yes & $330(89.9)$ & & $\mapsto-1$ & $7.32(4.88-10.97)$ & $<.001$ \\
\hline \multicolumn{6}{|l|}{ Understanding of PrEP } \\
\hline Excellent & $79(21.5)$ & & & Ref. & \\
\hline Good & $97(26.4)$ & $\longmapsto$ & & $0.14(0.06-0.34)$ & $<.001$ \\
\hline Low & $191(52.0)$ & $\longmapsto$ & & $0.04(0.02-0.10)$ & $<.001$ \\
\hline \multicolumn{6}{|c|}{ Effectiveness of PrEP on reducing the risk of HIV infection } \\
\hline Extremely effective & $206(56.1)$ & & & Ref. & \\
\hline Possibly effective & $68(18.5)$ & $\longmapsto$ & & $0.32(0.19-0.54)$ & $<.001$ \\
\hline Not sure & $91(24.8)$ & $1-1$ & & $0.05(0.04-0.08)$ & $<.001$ \\
\hline Ineffective & $2(0.5)$ & & $\longrightarrow$ & $0.20(0.02-1.98)$ & .17 \\
\hline \multicolumn{6}{|c|}{ Concerned about increasing the risk of other STDs } \\
\hline No & $332(90.5)$ & & & Ref. & \\
\hline Yes & $35(9.5)$ & $\longmapsto-1$ & & $0.42(0.27-0.64)$ & $<.001$ \\
\hline \multicolumn{6}{|c|}{ Concerned about poor adherence to PrEP } \\
\hline No & $206(56.1)$ & & & Ref. & \\
\hline Yes & $161(43.9)$ & $\mapsto-1$ & & $0.66(0.50-0.88)$ & .005 \\
\hline \multicolumn{6}{|c|}{ Concerned about lack of PrEP clinical guidelines } \\
\hline No & $322(87.7)$ & & & Ref. & \\
\hline Yes & $45(12.3)$ & $\mapsto-1$ & & $0.47(0.32-0.70)$ & $<.001$ \\
\hline \multicolumn{6}{|c|}{ Concerned about lack of drug indications } \\
\hline No & $333(90.7)$ & & & Ref. & \\
\hline \multirow[t]{2}{*}{ Yes } & $34(9.3)$ & $\mapsto-1$ & & $0.49(0.32-0.76)$ & .001 \\
\hline & & B.1 & 18 & 180 & \\
\hline
\end{tabular}

\section{Discussion}

\section{Principal Findings}

This is the first cross-sectional survey to assess the knowledge, attitudes, and experience of HIV clinicians regarding PrEP in China. While the proportion of clinicians surveyed who had heard of PrEP was only slightly less compared to the proportion in other developed countries, understanding of PrEP was much lower in China. Of those surveyed, 72.5\% (563/777) had heard of PrEP, which was slightly lower than the percentage in the United States (75\% to $96 \%$ ) [15-18] or in the United Kingdom (77\%) [19]. Only $30.8 \%$ of clinicians (239/777) rated their knowledge of PrEP as good or excellent in our study, which was much lower than previously reported in the United Kingdom (80\%) [19] and Canada (83.6\%) [20]. We also found that $47.2 \%$ (367/777) of the clinicians were willing to provide PrEP to high-risk groups. In comparison, the pooled prevalence of clinicians who were willing to prescribe PrEP in a meta-analysis was $66 \%$ in the United States [21], and the proportion found in Canada was $45.4 \%$ [20]. As there are no PrEP guidelines in China, standardized education and guidance on PrEP is limited, leading to low awareness on PrEP. In addition, as Chinese clinicians have a shorter period of professional training and the education levels of clinicians are relatively lower in remote areas, they may be younger and less experienced when beginning their clinical work compared with experienced clinicians in western countries such as the United States [18,22]. This shorter training period and the lower education levels may limit their PrEP-related knowledge and ability to prescribe PrEP to key populations; thus, this group of clinicians in China should be given priority for training. While this survey also found that about half of Chinese clinicians were willing to prescribe PrEP, their knowledge of PrEP was low compared to other developed countries.

We found that over half of clinicians (53\%) surveyed had seen high-risk groups actively seeking PrEP prescriptions, which is higher than the percentage in the United States (43\%) [13]. Although Chinese MSM have a limited understanding of PrEP $[26,29,30]$, they are willing to actively seek PrEP prescriptions, with a proportion of $75 \%$ in the relevant studies [2,25,31], while the proportion is about $60 \%$ in the United States [32].

Our study also identified the factors that promote or hinder the clinician in being willing to prescribe PrEP. Clinicians in infectious disease hospitals with longer work experience were more likely to be willing to prescribe PrEP for high-risk groups 
compared to those earlier in their careers. Previous studies have found that clinicians who attended more clinical training sessions were more likely to be willing to prescribe PrEP $[15,16,33]$. Thus, these clinicians with the longer careers could have been more likely to prescribe PrEP because they had more targeted clinical training and more extensive clinical experience over time. To increase the willingness to prescribe PrEP among those with less work experience, junior clinicians from general hospitals should specifically undergo PrEP-related training.

Concerns about the lack of PrEP clinical guidelines and drug indications were two independent barriers to clinicians' willingness to prescribe PrEP. Clinicians surveyed who were concerned about the lack of PrEP clinical guidelines had about half the odds of being willing to prescribe PrEP compared to those who were not concerned. Thus, development and implementation of PrEP guidelines could substantially increase the number of clinicians who are willing to prescribe PrEP and support the national implementation of PrEP [15,34]. The current Chinese guidelines, published in 2018, for diagnosis and treatment of HIV and AIDS only includes the definition of PrEP [35] and does not include any information on PrEP-related inclusion criteria, laboratory testing, PrEP regimens and adherence, or potential side effects. In addition, clinicians who were concerned about lack of PrEP indications were significantly less likely to be willing to prescribe PrEP compared to those who were not concerned. At the time this study was conducted, PrEP was not approved in China for HIV prevention. Thus, clinicians could be held liable for any possible side effects of PrEP, decreasing the number willing to prescribe PrEP. This potential problem was addressed in August 2020 when the National Medical Products Administration of China approved the use of Truvada for HIV prevention. Removing this barrier should lead to more clinicians who are willing to prescribe PrEP.

The results of this survey can support the future implementation of PrEP in China. First, by determining that concerns about lack of PrEP guidelines and drug indications leads to lower likelihood of being willing to prescribe PrEP, our study suggests that China must implement and promote national PrEP guidelines. While these guidelines are currently under development, it is imperative that they are published and distributed as soon as possible [23]. Second, our finding that less experienced clinicians were less likely to prescribe PrEP, combined with previous findings that PrEP-specific training led to clinicians being more willing to prescribe PrEP, suggest that junior clinicians should attend PrEP-specific training sessions [36].

\section{Strengths and Limitations}

This study was the first survey about PrEP-related knowledge, attitudes, and experience and barriers to prescribing PrEP among Chinese clinicians. By determining barriers in prescribing PrEP that must be addressed, our work will help promote PrEP implementation in China. We also conducted an online survey and obtained responses from all 31 provinces, while previous studies have conducted surveys only in a limited geographic area.

However, our study was limited by the small sample size compared to the total number of HIV clinicians in China, and the clinicians eligible for this study were not randomly sampled from all HIV clinicians in China. We also had few participants from certain provinces; in particular, provinces in the northwest where the proportion of clinicians who self-identified ethnically as Han was low. Therefore, our results are not representative of all HIV clinicians in China. Second, because this study was cross-sectional, we could not evaluate any causal relationship between potential factors and the clinicians' willingness to prescribe PrEP. Third, as this survey was based on self-reported knowledge and attitudes toward PrEP, their subjective answers could be impacted by response bias. Fourth, while the ratio of HIV clinicians from infectious disease hospitals and from general hospitals is generally 2:1 in China, in our study, the ratio was about $1: 1$. This lower representation of HIV clinicians from infectious disease hospitals could lead to selection bias and make our results less representative of HIV clinicians working in infectious disease hospitals. Lastly, as HIV prevention regulations vary substantially between different countries, we cannot extrapolate our China-specific results to other countries.

\section{Conclusions}

This survey found that a high proportion of Chinese clinicians had heard of PrEP, but many had limited understanding and incorrect knowledge of PrEP. The current lack of national clinical guidelines and drug indications for PrEP may lead to clinicians being less willing to prescribe PrEP. To address these barriers, the government must publish and promote national PrEP guidelines and clinicians with limited work experience should undergo PrEP-specific training to increase and promote use of PrEP among high-risk groups and reduce the risk of HIV infections.

\section{Acknowledgments}

The authors would like to thank all clinicians who participated in this study and research staff for their efforts in this study. This work was supported by the National Natural Science Foundation of China (grant 81872674), the Mega-Projects of National Science Research (13th Five-Year Plan; grant 2017ZX10201101-002-007), and the National Science and Technology Major Projects (grant 2018ZX10101-001-001-003). Additional funding support was provided by the Beijing Excellent Talent Plan (grant 2018000021223ZK04). The funders had no role in the study design, data collection and analysis, decision to publish, or preparation of the manuscript.

\section{Authors' Contributions}

HS, JX, and HD conceived and designed the study. HD collected and cleaned the data. JX and SC analyzed the data and interpreted the results. JX, HW, WT, XH, YJ, WG, SC, ZY, and SL wrote, revised, and interpreted the study results of the manuscript. HD 
and SC contributed equally as first authors. JX and HS contributed equally as corresponding authors. All authors have read and approved the final manuscript as submitted.

\section{Conflicts of Interest}

None declared.

\section{Multimedia Appendix 1}

Participant recruitment for the survey.

[DOCX File, 248 KB-Multimedia Appendix 1]

\section{Multimedia Appendix 2}

CHERRIES (Checklist for Reporting Results of Internet E-Surveys) checklist.

[DOCX File, 27 KB-Multimedia Appendix 2]

\section{Multimedia Appendix 3}

English version of the study questionnaire.

[DOCX File , 28 KB-Multimedia Appendix 3]

\section{Multimedia Appendix 4}

The distribution of HIV clinicians at the province level and economic level.

[DOCX File, 228 KB-Multimedia Appendix 4]

\section{References}

1. Koss CA, Charlebois ED, Ayieko J, Kwarisiima D, Kabami J, Balzer LB, SEARCH Collaboration. Uptake, engagement, and adherence to pre-exposure prophylaxis offered after population HIV testing in rural Kenya and Uganda: 72-week interim analysis of observational data from the SEARCH study. Lancet HIV 2020 Apr;7(4):e249-e261 [FREE Full text] [doi: 10.1016/S2352-3018(19)30433-3] [Medline: 32087152]

2. Peng L, Cao W, Gu J, Hao C, Li J, Wei D, et al. Willingness to use and adhere to HIV pre-exposure prophylaxis (PrEP) among men who have sex with men (MSM) in China. Int J Environ Res Public Health 2019 Jul 23;16(14):2620 [FREE Full text] [doi: 10.3390/ijerph16142620] [Medline: 31340482]

3. UNAIDS Data 2019. Geneva, Switzerland: UNAIDS; 2019. URL: https://www.unaids.org/en/resources/documents/2019/ 2019-UNAIDS-data [accessed 2021-05-22]

4. Guideline on When to Start Antiretroviral Therapy and on Pre-Exposure Prophylaxis for HIV. Geneva, Switzerland: World Health Organization; 2015 Sep. URL: https://www.who.int/hiv/pub/guidelines/earlyrelease-arv/en/ [accessed 2021-05-30]

5. Miles to Go: Closing Gaps, Breaking Barriers, Righting Injustices. Geneva, Switzerland: UNAIDS; 2018. URL: https:/ /www.unaids.org/en/resources/documents/2018/global-aids-update [accessed 2021-05-22]

6. Seizing the Moment: Tackling Entrenched Inequalities to End Epidemics. Geneva, Switzerland: UNAIDS; 2020. URL: https://www.unaids.org/en/resources/documents/2020/global-aids-report [accessed 2021-05-22]

7. A Guide to Taking a Sexual History. Atlanta, GA: Centers for Disease Control and Prevention; 2019. URL: https://www. cdc.gov/std/treatment/sexualhistory.pdf [accessed 2021-05-22]

8. Yusuf H, Fields E, Arrington-Sanders R, Griffith D, Agwu AL. HIV preexposure prophylaxis among adolescents in the US: A review. JAMA Pediatr 2020 Nov 01;174(11):1102-1108. [doi: 10.1001/jamapediatrics.2020.0824] [Medline: $\underline{32391878]}$

9. Blumenthal J, Jain S, Krakower D, Sun X, Young J, Mayer K, CCTG 598 Team. Knowledge is power! Increased provider knowledge scores regarding pre-exposure prophylaxis (PrEP) are associated with higher rates of PrEP prescription and future intent to prescribe PrEP. AIDS Behav 2015 May;19(5):802-810 [FREE Full text] [doi: 10.1007/s10461-015-0996-z] [Medline: 25616837]

10. Krakower D, Mayer KH. Engaging healthcare providers to implement HIV pre-exposure prophylaxis. Curr Opin HIV AIDS 2012 Nov;7(6):593-599 [FREE Full text] [doi: 10.1097/COH.0b013e3283590446] [Medline: 23032736]

11. Riddell J, Amico KR, Mayer KH. HIV preexposure prophylaxis: A review. JAMA 2018 Mar 27;319(12):1261-1268. [doi: 10.1001/jama.2018.1917] [Medline: 29584848]

12. Tao J, Qian H, Kipp AM, Ruan Y, Shepherd BE, Amico KR, et al. Effects of depression and anxiety on antiretroviral therapy adherence among newly diagnosed HIV-infected Chinese MSM. AIDS 2017 Dec 28;31(3):401-406 [FREE Full text] [doi: 10.1097/QAD.0000000000001287] [Medline: 27677168] 
13. Tellalian D, Maznavi K, Bredeek UF, Hardy WD. Pre-exposure prophylaxis (PrEP) for HIV infection: Results of a survey of HIV healthcare providers evaluating their knowledge, attitudes, and prescribing practices. AIDS Patient Care STDS 2013 Oct;27(10):553-559. [doi: 10.1089/apc.2013.0173] [Medline: 24053478]

14. Blackstock OJ, Moore BA, Berkenblit GV, Calabrese SK, Cunningham CO, Fiellin DA, et al. A cross-sectional online survey of HIV pre-exposure prophylaxis adoption among primary care physicians. J Gen Intern Med 2017 Jan;32(1):62-70. [doi: 10.1007/s11606-016-3903-z] [Medline: 27778215]

15. Terndrup C, Streed CG, Tiberio P, Black M, Davis J, Apfel A, et al. A cross-sectional survey of internal medicine resident knowledge, attitudes, behaviors, and experiences regarding pre-exposure prophylaxis for HIV infection. J Gen Intern Med 2019 Jul;34(7):1258-1278 [FREE Full text] [doi: 10.1007/s11606-019-04947-2] [Medline: 31020604]

16. Walsh JL, Petroll AE. Factors related to pre-exposure prophylaxis prescription by US primary care physicians. Am J Prev Med 2017 Jun;52(6):e165-e172 [FREE Full text] [doi: 10.1016/j.amepre.2017.01.025] [Medline: 28363410]

17. Hart-Cooper GD, Allen I, Irwin CE, Scott H. Adolescent health providers' willingness to prescribe pre-exposure prophylaxis (PrEP) to youth at risk of HIV infection in the United States. J Adolesc Health 2018 Aug;63(2):242-244. [doi: 10.1016/j.jadohealth.2018.03.016] [Medline: 29843969]

18. Sachdev DD, Stojanovski K, Liu AY, Buchbinder SP, Macalino GE. Intentions to prescribe preexposure prophylaxis are associated with self-efficacy and normative beliefs. Clin Infect Dis 2014 Jun;58(12):1786-1787 [FREE Full text] [doi: 10.1093/cid/ciu229] [Medline: 24729556]

19. Desai M, Gafos M, Dolling D, McCormack S, Nardone A. Healthcare providers' knowledge of, attitudes to and practice of pre-exposure prophylaxis for HIV infection. HIV Med 2016 Feb;17(2):133-142. [doi: 10.1111/hiv.12285] [Medline: 26172217]

20. Sharma M, Wilton J, Senn H, Fowler S, Tan DHS. Preparing for PrEP: Perceptions and readiness of Canadian physicians for the implementation of HIV pre-exposure prophylaxis. PLoS One 2014;9(8):e105283 [FREE Full text] [doi: 10.1371/journal.pone.0105283] [Medline: 25133648]

21. Zhang C, McMahon J, Fiscella K, Przybyla S, Braksmajer A, LeBlanc N, et al. HIV pre-exposure prophylaxis implementation cascade among health care professionals in the United States: Implications from a systematic review and meta-analysis. AIDS Patient Care STDS 2019 Dec;33(12):507-527. [doi: 10.1089/apc.2019.0119] [Medline: 31821044]

22. Smith DK, Mendoza MCB, Stryker JE, Rose CE. PrEP awareness and attitudes in a national survey of primary care clinicians in the United States, 2009-2015. PLoS One 2016;11(6):e0156592 [FREE Full text] [doi: 10.1371/journal.pone.0156592] [Medline: 27258374]

23. Xu J, Tang W, Zhang F, Shang H. PrEP in China: Choices are ahead. Lancet HIV 2020 Mar;7(3):e155-e157. [doi: 10.1016/S2352-3018(19)30293-0] [Medline: 31473165]

24. Wang H, Zhang Y, Mei Z, Jia Y, Leuba SI, Zhang J, et al. Protocol for a multicenter, real-world study of HIV pre-exposure prophylaxis among men who have sex with men in China (CROPrEP). BMC Infect Dis 2019 Aug 15;19(1):721 [FREE Full text] [doi: 10.1186/s12879-019-4355-y] [Medline: 31416439]

25. Han J, Bouey JZ, Wang L, Mi G, Chen Z, He Y, et al. PrEP uptake preferences among men who have sex with men in China: Results from a national internet survey. J Int AIDS Soc 2019 Feb;22(2):e25242 [FREE Full text] [doi: 10.1002/jia2.25242] [Medline: 30724470]

26. Zhang Y, Peng B, She Y, Liang H, Peng H, Qian H, et al. Attitudes toward HIV pre-exposure prophylaxis among men who have sex with men in western China. AIDS Patient Care STDS 2013 Mar;27(3):137-141 [FREE Full text] [doi: 10.1089/apc.2012.0412] [Medline: 23425017]

27. Wang Z, Lau JTF, Fang Y, Ip M, Gross DL. Prevalence of actual uptake and willingness to use pre-exposure prophylaxis to prevent HIV acquisition among men who have sex with men in Hong Kong, China. PLoS One 2018;13(2):e0191671 [FREE Full text] [doi: 10.1371/journal.pone.0191671] [Medline: 29432470]

28. Gauvreau K, Pagano M. Hypothesis tests. Nutrition 1993;9(2):186-187. [Medline: $\underline{8485335]}$

29. Zhou F, Gao L, Li S, Li D, Zhang L, Fan W, et al. Willingness to accept HIV pre-exposure prophylaxis among Chinese men who have sex with men. PLoS One 2012;7(3):e32329 [FREE Full text] [doi: 10.1371/journal.pone.0032329] [Medline: 22479320]

30. Meyers K, Wu Y, Qian H, Sandfort T, Huang X, Xu J, et al. Interest in long-acting injectable PrEP in a cohort of men who have sex with men in China. AIDS Behav 2018 Apr;22(4):1217-1227 [FREE Full text] [doi: 10.1007/s10461-017-1845-z] [Medline: 28707025]

31. Wei S, Zou Y, Xu Y, Liu J, Nong Q, Bai Y, et al. Acceptability and influencing factors of pre-exposure prophylaxis among men who have sex with men in Guangxi. Zhonghua Liu Xing Bing Xue Za Zhi 2011 Aug;32(8):786-788. [Medline: 22093468]

32. Sullivan PS, Sanchez TH, Zlotorzynska M, Chandler CJ, Sineath RC, Kahle E, et al. National trends in HIV pre-exposure prophylaxis awareness, willingness and use among United States men who have sex with men recruited online, 2013 through 2017. J Int AIDS Soc 2020 Mar;23(3):e25461 [FREE Full text] [doi: 10.1002/jia2.25461] [Medline: $\underline{32153119]}$

33. Henny KD, Duke CC, Geter A, Gaul Z, Frazier C, Peterson J, et al. HIV-related training and correlates of knowledge, HIV screening and prescribing of nPEP and PrEP among primary care providers in Southeast United States, 2017. AIDS Behav 2019 Nov;23(11):2926-2935 [FREE Full text] [doi: 10.1007/s10461-019-02545-1] [Medline: $\underline{31172333}$ ] 
34. Ryskina KL, Dine CJ, Kim EJ, Bishop TF, Epstein AJ. Effect of attending practice style on generic medication prescribing by residents in the clinic setting: An observational study. J Gen Intern Med 2015 Sep;30(9):1286-1293 [FREE Full text] [doi: 10.1007/s11606-015-3323-5] [Medline: 26173522]

35. AIDS and Hepatitis C Professional Group, Society of Infectious Diseases, Chinese Medical Association, Chinese Center for Disease Control and Prevention. Chinese guidelines for diagnosis and treatment of HIV/AIDS (2018) [Article in Chinese]. Zhonghua Nei Ke Za Zhi 2018 Dec 01;57(12):867-884. [doi: 10.3760/cma.j.issn.0578-1426.2018.12.002] [Medline: 30486555]

36. Clement ME, Seidelman J, Wu J, Alexis K, McGee K, Okeke NL, et al. An educational initiative in response to identified PrEP prescribing needs among PCPs in the Southern US. AIDS Care 2017 Oct 03;30(5):650-655. [doi: 10.1080/09540121.2017.1384534] [Medline: 28971705]

\author{
Abbreviations \\ aOR: adjusted odds ratio \\ CHERRIES: Checklist for Reporting Results of Internet E-Surveys \\ MSM: men who have sex with men \\ OR: odds ratio \\ PrEP: pre-exposure prophylaxis \\ TDF/FTC: tenofovir disoproxil fumarate/emtricitabine \\ WHO: World Health Organization
}

\author{
Edited by G Eysenbach; submitted 10.09.20; peer-reviewed by Z Ren, MDG Pimentel, A Azzam; comments to author 21.10.20; revised \\ version received 13.12.20; accepted 15.04.21; published 04.06.21 \\ Please cite as: \\ Cui S, Ding H, Huang X, Wang H, Tang W, Leuba SI, Ye Z, Jiang Y, Geng W, Xu J, Shang H \\ Factors Influencing Clinicians' Willingness to Prescribe Pre-exposure Prophylaxis for Persons at High Risk of HIV in China: \\ Cross-sectional Online Survey Study \\ JMIR Public Health Surveill 2021;7(6):e24235 \\ URL: https://publichealth.jmir.org/2021/6/e24235 \\ doi: $10.2196 / 24235$ \\ PMID:
}

(CSitong Cui, Haibo Ding, Xiaojie Huang, Hui Wang, Weiming Tang, Sequoia I Leuba, Zehao Ye, Yongjun Jiang, Wenqing Geng, Junjie Xu, Hong Shang. Originally published in JMIR Public Health and Surveillance (https://publichealth.jmir.org), 04.06.2021. This is an open-access article distributed under the terms of the Creative Commons Attribution License (https://creativecommons.org/licenses/by/4.0/), which permits unrestricted use, distribution, and reproduction in any medium, provided the original work, first published in JMIR Public Health and Surveillance, is properly cited. The complete bibliographic information, a link to the original publication on https://publichealth.jmir.org, as well as this copyright and license information must be included. 